\title{
Doxycycline Added to Prednisolone in Outpatient-Treated Acute Exacerbations of COPD: A Cost-Effectiveness Analysis Alongside a Randomised Controlled Trial
}

\author{
Aureliano Paolo Finch ${ }^{1} \cdot$ Patricia van Velzen ${ }^{2} \cdot$ Gerben ter Riet $^{3} \cdot$ Peter J. Sterk $^{2} \cdot$ Jan M. Prins ${ }^{4} \cdot$ Judith E. Bosmans $^{1,5}$
}

Published online: 19 December 2018

(c) The Author(s) 2018

\begin{abstract}
Background Most patients with mild to severe chronic obstructive pulmonary disease (COPD) experience exacerbations, which are also associated with increased healthcare costs. Despite limited evidence of antibiotics' benefits for exacerbations in outpatients, antibiotics are frequently prescribed. The aim of this study was to investigate whether doxycycline added to prednisolone is cost-effective compared to placebo plus prednisolone for the treatment of COPD acute exacerbations.

Methods An economic evaluation from the societal perspective was performed alongside a 2-year randomised trial in 301 COPD patients in the Netherlands. The primary outcome was cost per quality-adjusted life year (QALY). The secondary outcome was cost per exacerbation prevented. Healthcare utilisation and loss of productivity were measured using retrospective questionnaires and clinical report forms. Missing data were imputed using multiple imputations by chained equations. Bootstrapping was employed to estimate statistical uncertainty surrounding cost-effectiveness outcomes. A sensitivity analysis from the healthcare perspective was performed.

Results On average, costs in the doxycycline group were $€ 898$ higher than in the placebo group [95\% confidence interval (CI) -2617 to 4409] for the 2 years of follow-up. QALY values were higher in the doxycycline group $(0.03 ; 95 \%$ CI -0.00 to 0.06 ), but patients in this group suffered 0.01 more exacerbations than patients in the placebo group (95\% CI -0.14 to 0.11). Cost-effectiveness acceptability curves showed that the probability of doxycycline being cost-effective compared to placebo was $61 \%$ and $43 \%$ at a willingness-to-pay threshold of $€ 34,000$ per QALY and per exacerbation avoided, respectively. The sensitivity analysis showed similar results from the healthcare system perspective.

Conclusions In patients with mild to severe COPD treated for exacerbations in an outpatient setting, doxycycline added to prednisolone is not cost-effective compared to prednisolone plus placebo over a 2-year period.
\end{abstract}

Aureliano Paolo Finch and Patricia van Velzen equally contributed to this work.

Aureliano Paolo Finch

a.p.finch@vu.nl

1 Department of Health Sciences, Faculty of Earth and Life Sciences, VU University Amsterdam, De Boelelaan 1105, 1081 HV Amsterdam, The Netherlands

2 Department of Respiratory Medicine, Amsterdam UMC, University of Amsterdam, Amsterdam, The Netherlands

3 Department of General Practice, Amsterdam UMC, University of Amsterdam, Amsterdam, The Netherlands

4 Division of Infectious Diseases, Department of Internal Medicine, Amsterdam UMC, University of Amsterdam, Amsterdam, The Netherlands

5 EMGO+ Institute for Health and Care Research, Faculty of Earth and Life Sciences, VU University Amsterdam, Amsterdam, The Netherlands

\section{Key Points for Decision Makers}

Doxycycline added to prednisolone resulted in higher costs and higher quality-adjusted life year (QALY) values compared to prednisolone plus placebo in patients with mild to severe chronic obstructive pulmonary disease.

The probability of doxycycline being cost-effective was $61 \%$ at a willingness-to-pay threshold of $€ 34,000$ per QALY.

Doxycycline added to prednisolone is not cost-effective compared to prednisolone plus placebo over a 2-year period. 


\section{Introduction}

Chronic obstructive pulmonary disease (COPD) is a prevalent disease, characterised by non-fully reversible airflow limitation $[1,2]$. According to recent estimates, 65 million people are affected by COPD worldwide, and the disease is predicted to become the third most common cause of death by 2020 [3]. Most patients with COPD experience exacerbations, which are characterised by an acute worsening of respiratory symptoms [1, 4]. Exacerbations have a major impact on patients' physical and psychological wellbeing [5], and are associated with a reduced quality of life [6], a faster decline in lung function [7], and increased mortality [8]. Exacerbations are one of the most important drivers of the total COPD costs on the healthcare system, especially when hospitalisation is necessary, and impose a large economic burden on society [9]. In the Dutch context in particular, exacerbations are the main cost driver, together with medications [10].

Most exacerbations are treated in an outpatient setting. Treatment of exacerbations consists of oral corticosteroids with or without antibiotics [1,4]. Despite limited shortterm benefits [11], antibiotics are frequently prescribed. Two retrospective studies $[12,13]$ and one randomised controlled trial [14] suggested that antibiotics prolong time to the next exacerbation. However, evidence on the cost-effectiveness of antibiotics for the treatment of COPD exacerbations in an outpatient setting is scarce [15].

Recently, a randomised controlled trial conducted by the current research group investigated the long-term clinical effectiveness of doxycycline versus placebo added to prednisolone for the treatment of COPD exacerbations in an outpatient setting [16]. Differently from what it was hypothesised, it found that treatment with antibiotics did not prolong time to the next exacerbation. However, the randomised controlled trial could not exclude the possibility that short-term treatment nonresponse was lower in patients treated with antibiotics, which might result in lower total costs in this group. Hence, despite not being clinically effective, treatment with doxycycline might still be cost-effective. To assess whether this was the case, we conducted a cost-effectiveness analysis alongside the previously reported randomised controlled trial, the results of which are presented here.

\section{Methods}

\subsection{Trial Design}

An economic evaluation from the societal perspective was conducted alongside the TEXACOLD study in The Netherlands. This was a randomised, double-blind, controlled trial investigating the long-term clinical and cost-effectiveness of doxycycline plus prednisolone versus placebo plus prednisolone for the treatment of COPD exacerbations in an outpatient setting. The trial protocol was approved by the ethics committee of the Academic Medical Centre at the University of Amsterdam, and patients gave their written informed consent. Participants, investigators and those assessing outcomes were blinded to intervention assignment. Full details of the trial are available in Van Velzen et al. [16].

\subsection{Participants}

Participants were recruited from nine teaching hospitals and three primary care practices in The Netherlands. Patients were eligible for inclusion if they were 45 years or older, had a clinical diagnosis of mild-to-severe COPD, defined as a post-bronchodilator forced expiratory volume in $1 \mathrm{~s}$ (FEV1) to forced vital capacity (FVC) ratio of $\leq 0.7$ and a post-bronchodilator FEV1 of $\geq 30 \%$, according to Global Initiative for Chronic Obstructive Lung Disease (GOLD) and American Thoracic Society and European Respiratory Society criteria $[1,2]$, had a smoking history of at least 10 pack-years, and had suffered one or more exacerbations during the previous 3 years, with the limitation that the last exacerbation ended less than 4 weeks before recruitment. Patients were not eligible if they did not speak Dutch, had poor cognitive abilities, were pregnant, had a known allergy to doxycycline, or had a life expectancy shorter than 1 month.

All patients entered a prospective cohort. In the case of an exacerbation, cohort participants were randomly assigned to a 7-day course of doxycycline $100 \mathrm{mg}$ (first day $200 \mathrm{mg}$ ) or to a control group, in a 1:1 ratio. An exacerbation of COPD was defined as an event characterised by a change in the patient's baseline dyspnoea, cough, or sputum beyond dayto-day variability, sufficient to warrant a change in management other than optimising bronchodilator therapy $[1,2]$.

Patients in both groups were administered oral corticosteroids, i.e. prednisolone $30 \mathrm{mg}$ daily for 10 days. If further exacerbations occurred during the 2-year follow-up period, patients received the same medications as by treatment allocation.

\subsection{Procedures}

Baseline data, including demographics, GOLD stage, smoking history and medication use, were collected at the time of inclusion in the prospective cohort and recorded in a standardised electronic case record form (eCRF, Oracle Clinical).

Health status was measured using the Dutch version of the EQ-5D-3L. The EQ-5D-3L consists of two parts: a questionnaire and a visual analogue scale (VAS). The questionnaire self-reported health status ranges from 11111 (no problems in any of the five dimensions) to 33333 (extreme problems in all the five dimensions). The VAS ranges from 
0 (worst imaginable health) to 100 (best imaginable health) [17]. The EQ-5D-3L was administered at randomisation, at month 1 after randomisation, month 3, and every 3 months thereafter until month 24 .

\subsection{Resource Use and Unit Costs $(€, 2017)$}

Information on resource use was collected retrospectively at month 1 after randomisation, month 3, and every 3 months thereafter until month 24; patients were asked to respond to selected questions of the Trimbos/iMTA Labour and Health questionnaire [18]. Given the societal perspective employed in this economic evaluation, all-cause resource use was collected, i.e. not only resource use related to COPD. Each patient self-reported hospitalisation was verified by contacting the hospital where hospitalisation took place and requesting a hospital discharge letter. Healthcare costs included intervention costs, i.e. doxycycline and prednisolone; primary care costs, e.g. general practitioner (GP) and physiotherapist visits; secondary care costs, e.g. hospital admissions and intensive care unit admissions; diagnostics costs, e.g. computed tomography (CT) scans, X-rays and blood tests; support equipment costs, e.g. ventilators, wheelchairs and walkers; and other costs, e.g. nursing home residency. Patient and family costs included informal care and unpaid help. Costs were estimated multiplying the units of resource use by their standard cost according to the Dutch guidelines for economic evaluation [19]. These standard costs take into account labour, overhead and material costs. The drug prescription costs were obtained from the Royal Dutch Society of Pharmacy [20].

Loss of productivity due to absenteeism and presenteeism was calculated using the friction cost method. Differently from the human capital method, the friction cost method assumes that after a given period of absence from employment, the sick employee is replaced [21]. This study used a friction period of 85 days. Hence, productivity losses are generated only during that time period. Absenteeism was assessed by asking responders how many days of paid work they missed due to health problems. Presenteeism was assessed by asking responders how many hours they would need to work to make up for the time lost while at work due to health problems. Costs of absenteeism and presenteeism were calculated based on gender-specific income values of the Dutch population [19]. All costs were inflated to the year 2017 using consumer price indexes. The main unit costs used for the cost calculation are presented in Table 1 .

\subsection{Outcome Measures}

As recommended by the Zorginstituut in The Netherlands [22] and the National Institute for Health and Care
Table 1 Main unit costs used for cost calculation

\begin{tabular}{|c|c|c|}
\hline Resources & $€(2017$ values $)$ & Source \\
\hline \multicolumn{3}{|l|}{ Direct costs } \\
\hline Intensive care unit (day) & 2041.19 & (19) \\
\hline Hospitalisation (day) & 448.75 & (19) \\
\hline Accident and emergencies admission & 262.36 & (19) \\
\hline GP office visit & 33.42 & (19) \\
\hline GP home visit & 50.65 & (19) \\
\hline GP phone call & 17.22 & (19) \\
\hline Specialist visit & 113.45 & (19) \\
\hline Nurse (h) & 21.27 & (19) \\
\hline Help at home (day) & 73.94 & (19) \\
\hline Nursing home (day) & 170.18 & (19) \\
\hline Rehabilitation (day) & 154.98 & (19) \\
\hline CT scan & 136.75 & (19) \\
\hline$X$-ray chest & 46.04 & (19) \\
\hline Blood tests & 106.35 & (19) \\
\hline Wheelchair/walker & 455.85 & (19) \\
\hline Oxygen concentrator & 2039.16 & (19) \\
\hline \multicolumn{3}{|l|}{ Productivity losses } \\
\hline $\begin{array}{l}\text { Absenteeism from paid labour woman } \\
\text { (h) }\end{array}$ & 32.01 & (19) \\
\hline Absenteeism from paid labour man (h) & 38.39 & (19) \\
\hline $\begin{array}{l}\text { Presenteeism from paid labour woman } \\
\text { (h) }\end{array}$ & 32.01 & (19) \\
\hline Presenteeism from paid labour man (h) & 38.39 & (19) \\
\hline \multicolumn{3}{|l|}{ Interventions } \\
\hline Prednisolone + doxycycline & 38.47 & (20) \\
\hline Prednisolone alone & 31.52 & $(20)$ \\
\hline
\end{tabular}

$C T$ computed tomography, GP general practitioner

Excellence in the UK [23], the primary outcome for this cost-effectiveness study was quality-adjusted life years (QALYs). QALYs are an index that multiplies the time patients spend in a given health state with a utility value that represents the health-related quality of life (HRQoL) associated with that health state. Transitions between health states were considered to be linear. Utility values were obtained using the Dutch version of the EQ-5D-3L with the Dutch tariff [24]. The EQ-5D-3L was chosen as it is the most widely used measure for economic evaluations worldwide [25] and it has been deemed valid for COPD populations [26].

The number of exacerbations during the 2 years after randomisation was the secondary outcome. This was chosen as clinical studies have shown that prescribing antibiotics for exacerbations might reduce their frequency [12-14]. A minimum interval of 3 weeks between subsequent exacerbations was defined [27], to avoid counting an exacerbation not responding to treatment as a next exacerbation. 


\subsection{Analysis}

The study sample size $(n=301)$ was calculated to ensure at least $251 \mathrm{~s}$ exacerbations, with a statistical power of $80 \%$ for the outcome occurrence of a second exacerbation. The economic evaluation was conducted according to the intention-to-treat principle. Missing costs and effectiveness data were imputed using multiple imputations by chained equations, stratified by treatment group [28]. The imputation model included all outcome variables, characteristics differing between groups at baseline, variables related to missing data and variables related to outcome variables. The model was used to create 25 complete datasets, after which the loss of efficiency was $1 \%$ [28]. Non-normal distribution of costs was accounted for by using predictive mean matching in the multiple imputation by chained equations procedure [29]. Rubin's rules were used to pool effects and costs from the imputed datasets [30].

Seemingly unrelated regressions were employed to estimate differences in costs and effects, adjusting for baseline HRQoL. Seemingly unrelated regressions were chosen as they take into account the covariance between costs and effects in estimating the error terms [31]. For the second year of the randomised clinical trial, $4 \%$ discounting was employed for costs, and $1.5 \%$ discounting was employed for effects [22]. Seemingly unrelated regression analysis assumes bivariate normality, an assumption that is clearly violated by the distribution of costs and QALYs. Therefore, joint uncertainty around costs and effects was estimated using bias-corrected and accelerated bootstrapping with 5000 replications [32]. Bootstrapped costs and effects were plotted on a cost-effectiveness plane (CE plane) to graphically present the uncertainty surrounding the incremental cost-effectiveness ratio (ICER) [33]. In addition, a costeffectiveness acceptability curve (CEAC) was estimated in order to present the probability that the treatment is costeffective compared to the control at different ceiling ratios, i.e. the amount society is willing to pay to gain one unit of effect [34]. In order to interpret the CEAC for QALYs, the commonly used threshold of $£ 20,000-30,000$ per QALY (€22,000-34,000 per QALY) was employed [23]. Analyses were performed using Stata/MP $14.1^{\circledR}$.

\subsection{Sensitivity Analysis}

The primary analysis was based on costs from a societal perspective. In addition, a sensitivity analysis was performed with the objective of assessing the cost-effectiveness for the primary and secondary outcomes from the healthcare system perspective. This choice was made as health technology assessment bodies such as the National Institute for Health and Care Excellence request economic evaluations to be performed from this perspective [23].

\section{Results}

\subsection{Participants}

Between 1 December 2010 and 15 September 2012, 887 patients were enrolled in the cohort, of whom 305 had an exacerbation and were randomly allocated to the doxycycline (152 participants) or the placebo group (153 participants). Four participants, two in each arm, were incorrectly randomly allocated because of failed eligibility criteria and were excluded. A flow-chart of the allocation process is provided in Fig. 3 in "Appendix". As shown in Table 2, background characteristics of the included participants did not differ between treatment arms, except for the placebo group comprising a higher percentage of women (46\% vs $35 \%$ in the doxycycline group).

Complete follow-up data for the EQ-5D-3L were obtained from $24 \%$ of the participants. Data on the EQ-5D-3L was missing for $20 \%$ of participants at baseline and 1 month follow-up, $22 \%$ at 3 and 6 months, $31 \%$ at 9 months, $30 \%$ at 12 months, $28 \%$ at 15 months, $29 \%$ at 18 months and $36 \%$ at 21 and 24 months. All participants had complete followup data for the secondary outcome, number of exacerbations during the 2 years after randomisation. Background characteristics did not differ between participants with and without complete follow-ups, except for the FVC percentage, which was statistically significantly higher for the complete cases.

\subsection{Costs and Effects}

Table 3 reports the mean costs and effects per patient for the doxycycline and placebo groups over the 2 years of follow-up, and their bootstrapped mean differences. Total costs amounted to $€ 11,840$ for the doxycycline group and $€ 10,942$ for the control group: difference $€ 898$ [95\% confidence interval (CI) - 2617 to 4409]. Higher costs in the doxycycline arm were mainly due to higher absenteeism (€648; 95\% CI - 561 to 2060) and tertiary care costs (€390; $95 \% \mathrm{CI}-2474$ to 3648$)$. The costs for support equipment, e.g. respirators, wheelchairs, etc., was higher in the control group ( $-€ 226 ; 95 \% \mathrm{CI}-450$ to 2 ). Costs in all remaining cost categories were similar across treatment arms.

QALYs were 1.44 in the doxycycline group and 1.41 in the control (mean difference $0.03 ; 95 \% \mathrm{CI}-0.00$ to 0.07 ). However, patients treated with doxycycline tended to suffer an average of 0.01 exacerbations more than those treated with placebo (95\% CI -0.14 to 0.11$)$. None of these differences were statistically significant.

\subsection{Cost-Effectiveness Analysis}

Table 4 reports the results of the cost-effectiveness analysis. For QALYs, the ICER was 32,482, meaning that 1 QALY 
Table 2 Background characteristics of participants by treatment group

\begin{tabular}{|c|c|c|}
\hline Characteristics & Doxycycline $(n=150)$ & Control $(n=151)$ \\
\hline Age (years) & $65.8(9.3)$ & $66.4(9.5)$ \\
\hline Female (sex) & $52(35 \%)$ & $70(46 \%)$ \\
\hline \multicolumn{3}{|l|}{ Comorbidities } \\
\hline Myocardial infarction & $24(16 \%)$ & $32(21 \%)$ \\
\hline Heart failure & $12(8 \%)$ & $9(6 \%)$ \\
\hline Cerebrovascular disorder & $9(6 \%)$ & $14(9 \%)$ \\
\hline Diabetes mellitus & $16(11 \%)$ & $15(10 \%)$ \\
\hline Smoking history (pack years) & $47.2(36.8 \%)$ & $50.8(31.7 \%)$ \\
\hline Current smoker & $49(33 \%)$ & $65(43 \%)$ \\
\hline \multicolumn{3}{|l|}{ GOLD stage } \\
\hline 1 & $21(14 \%)$ & $19(13 \%)$ \\
\hline 2 & $81(54 \%)$ & $84(56 \%)$ \\
\hline 3 & $48(32 \%)$ & $48(32 \%)$ \\
\hline \multicolumn{3}{|l|}{ Baseline lung function } \\
\hline FEV1 (L) & $1.75(0.6)$ & $1.63(0.6)$ \\
\hline FEV1 (\% predicted) & $61.1(18.0)$ & $60.5(17.7)$ \\
\hline $\mathrm{FVC}(\mathrm{L})$ & $3.62(1.01)$ & $3.36(1.11)$ \\
\hline FVC (\% predicted) & $98.3(22.2)$ & $94.6(26.5)$ \\
\hline FEV1 to FVC ratio & $0.49(0.1)$ & $0.49(0.1)$ \\
\hline Number of exacerbations per year in previous 3 years & $1.3(0.67-2.3)$ & $1.3(0.67-2.0)$ \\
\hline St George’s Respiratory Questionnaire ${ }^{\dagger}$ & $46.3(18.4)$ & $48.0(17.7)$ \\
\hline Time from inclusion in cohort to inclusion in the trial (days) & $123(53-250)$ & $116(49-281)$ \\
\hline Prescription of oral corticosteroids & $143(95 \%)$ & $143(95 \%)$ \\
\hline
\end{tabular}

Data are $n(\%)$, mean (SD), or median (IQR)

Data are based on Van Velzen et al. [16]

$G O L D$ Global Initiative for chronic obstructive lung disease, $F E V 1$ forced expiratory volume in $1 \mathrm{~s}, F V C$ forced vital capacity, $I Q R$ interquartile range, $S D$ standard deviation

${ }^{\ddagger}$ All patients were current or former smokers

${ }^{\dagger}$ Higher scores represent worse quality of life

Table 3 Mean costs ( $€$ for 2017) and effectiveness per participant in the doxycycline and placebo groups for the 2-year follow-up

\begin{tabular}{lccc}
\hline Cost category & $\begin{array}{l}\text { Doxycycline }(n=150) \\
\text { mean }(95 \% \text { CI })\end{array}$ & Control $(n=151)$ mean (95\% CI) & Mean difference (95\% CI) \\
\hline Intervention & $139(125$ to 152$)$ & $113(102$ to 125$)$ & $26(8$ to 42$)$ \\
Primary care & $54(39$ to 68$)$ & $85(59$ to 110$)$ & $-31(-5$ to -61$)$ \\
Secondary care & $571(458$ to 683$)$ & $546(434$ to 657$)$ & $25(-135$ to 182$)$ \\
Tertiary care and accident and emergencies & $5236(2824$ to 7648$)$ & $4846(2892$ to 6800$)$ & $390(-2474$ to 3648$)$ \\
Diagnostics & $383(307$ to 459$)$ & $387(317$ to 459$)$ & $-4(-104$ to 103$)$ \\
Other costs, e.g. nursing homes & $287(15$ to 556$)$ & $365(76$ to 652$)$ & $-78(-461$ to 327$)$ \\
Support equipment, e.g. ventilators, wheelchairs, etc. & $1473(1309$ to 1635$)$ & $1699(1532$ to 1865$)$ & $-226(-450$ to 2$)$ \\
Paid or unpaid help & $1132(921$ to 1339$)$ & $1081(903$ to 1308$)$ & $51(-218$ to 332$)$ \\
Productivity losses: absenteeism & $1664(596$ to 2732$)$ & $1016(255$ to 1775$)$ & $648(-561$ to 2060$)$ \\
Productivity losses: presenteeism & $901(761$ to 1041$)$ & $804(676$ to 930$)$ & $97(-90$ to 286$)$ \\
Total cost from societal perspective & $11840(9196$ to 14490$)$ & $10942(8601$ to 13291$)$ & $898(-2617$ to 4409$)$ \\
Total cost from healthcare system perspective & $6670(4222$ to 9121$)$ & $6342(4313$ to 8375$)$ & $328(-2791$ to 4409$)$ \\
Quality-adjusted life years & $1.44(1.37$ to 1.50$)$ & $1.41(1.33$ to 1.47$)$ & $0.03(-0.00$ to 0.07$)$ \\
Number of exacerbations & $2.71(2.35$ to 3.06$)$ & $2.70(2.33$ to 3.07$)$ & $0.01(-0.14$ to 0.11$)$ \\
\hline
\end{tabular}

CI confidence interval 
gained in the doxycycline group was associated with an extra cost of $€ 32,482$ compared to the control group. Figure 1a graphically presents the distribution of cost and effect pairs in the CE plane. As can be seen, $70 \%$ of pairs were located in the north quadrants, showing that doxycycline is likely to be more expensive than placebo. Pairs were mostly located in the east quadrants ( $76 \%$ vs $24 \%$ ), highlighting that there is a higher probability of doxycycline being more effective than placebo. Figure $1 b$ reports the CEAC for the primary outcome QALYs. It shows that at a willingness-to-pay threshold of $€ 0$ per QALY, the probability that doxycycline is cost-effective is $26 \%$, while at a willingness-to-pay threshold of $€ 34,000$ per QALY this increases to $61 \%$.

For the number of exacerbations avoided, an ICER of $-60,194$ was found. This meant that one additional exacerbation in the doxycycline group was associated with an increased cost of $€ 60,194$ in comparison with the control. Once again, cost-effect pairs were mostly concentrated in

Table 4 Difference in costs ( $€$ for 2017) and effectiveness, ICER and distribution in the CE plane, adjusted for baseline HRQoL

\begin{tabular}{|c|c|c|c|c|c|c|c|c|c|}
\hline \multicolumn{2}{|l|}{ Analysis } & \multirow[t]{2}{*}{ Outcome } & \multirow[t]{2}{*}{$\Delta \mathrm{C}(95 \% \mathrm{CI})(€)$} & \multirow{2}{*}{$\begin{array}{l}\Delta \mathrm{E}(95 \% \mathrm{CI}) \\
\text { (points) }\end{array}$} & \multirow{2}{*}{$\begin{array}{l}\text { ICER } \\
(€ / \text { point })\end{array}$} & \multicolumn{4}{|c|}{ Distribution CE plane (\%) } \\
\hline Perspective & Type of analysis & & & & & $\begin{array}{l}\mathrm{NE}^{1} \\
(\%)\end{array}$ & $\begin{array}{l}\mathrm{SE}^{2} \\
(\%)\end{array}$ & $\begin{array}{l}\mathrm{SW}^{3} \\
(\%)\end{array}$ & $\mathrm{NW}^{4}(\%)$ \\
\hline Societal & Main analysis & QALYs (range 0-1) & 951 ( -40 to 1860$)$ & $0.03(-0.06$ to 0.00$)$ & 32,482 & 52 & 24 & 6 & 18 \\
\hline Societal & Main analysis & $\begin{array}{l}\text { Number of exacerba- } \\
\text { tions }(0-\infty)\end{array}$ & $951(-40$ to 1860$)$ & $-0.01(-0.14$ to 0.11$)$ & $-60,194$ & 30 & 17 & 13 & 40 \\
\hline Healthcare system & Sensitivity analysis I & QALYs (range 0-1) & $361(-453$ to 1178$)$ & $0.03(-0.00$ to 0.06$)$ & 12,358 & 42 & 33 & 8 & 17 \\
\hline Healthcare system & Sensitivity analysis II & $\begin{array}{l}\text { Number of exacerba- } \\
\text { tions }(0-\infty)\end{array}$ & $361(-453$ to 1178$)$ & $-0.01(-0.14$ to 0.11$)$ & $-22,905$ & 25 & 23 & 19 & 33 \\
\hline
\end{tabular}

$C E$ cost-effectiveness, $C I$ confidence interval, $H R Q o L$ health-related quality of life, ICER incremental cost-effectiveness ratio, $N E$ north-east quadrant, $N W$ north-west quadrant, QALY quality-adjusted life year, $S E$ south-east quadrant, $S W$ south-west quadrant

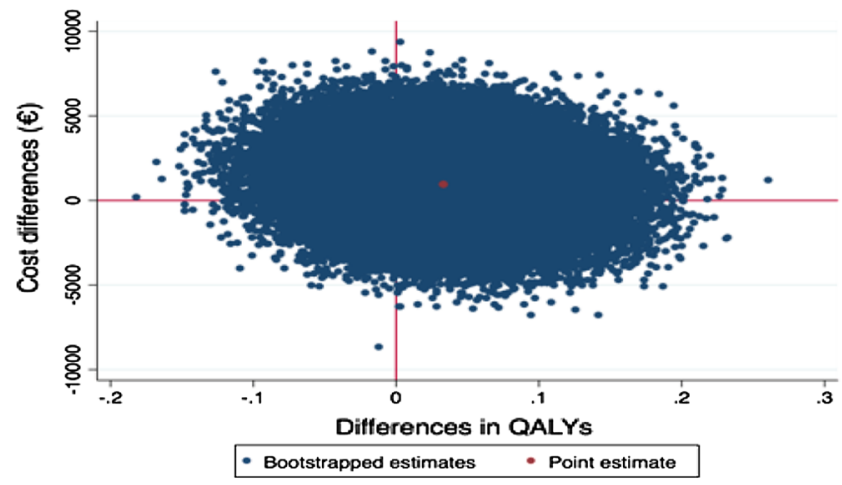

(A) Cost-effectiveness plane for QALYs

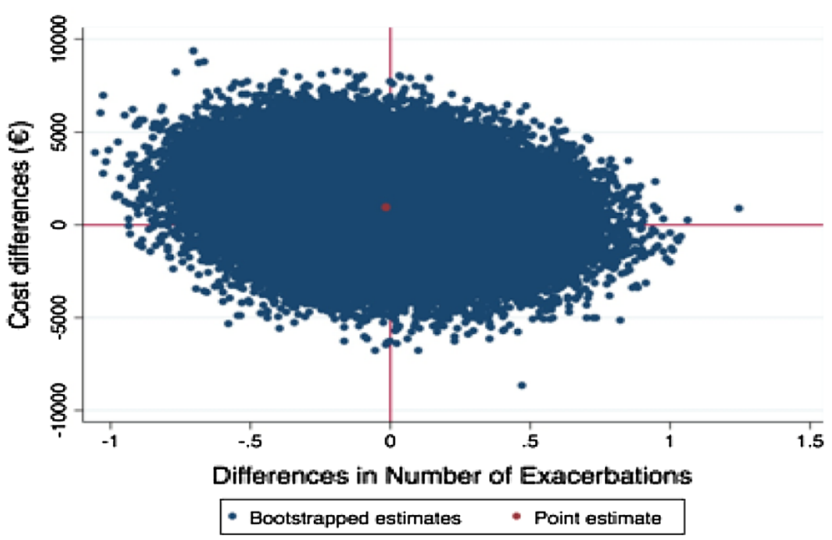

(C) Cost-effectiveness plane for Number of exacerbations

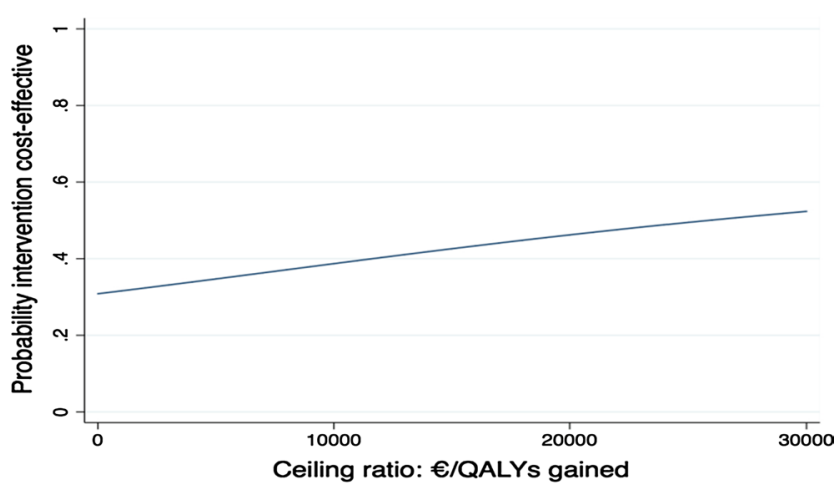

(B) Cost-effectiveness acceptability curve for QALYs

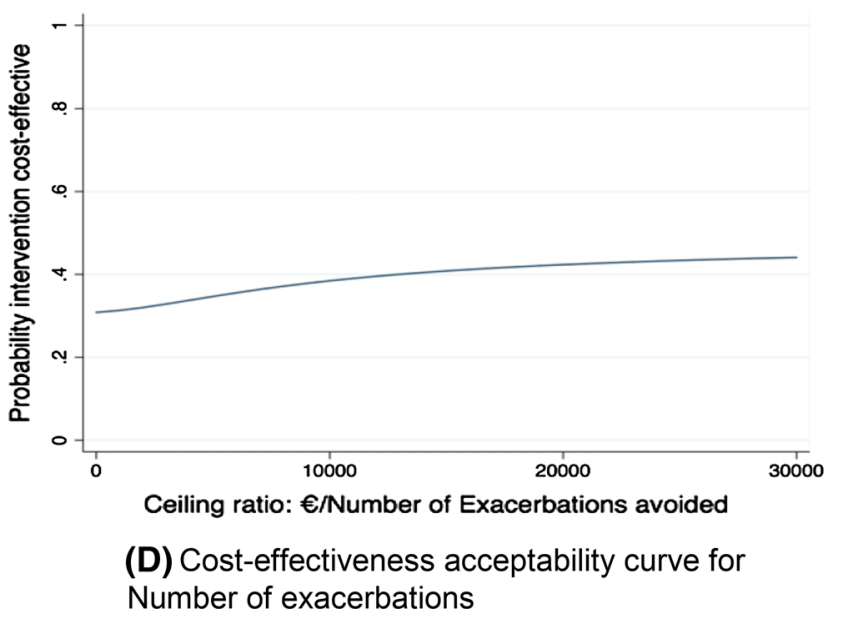

Fig. 1 Main analysis cost-effectiveness plane and cost-effectiveness acceptability curve for QALYs and number of exacerbations. QALY qualityadjusted life year 
the north quadrants, i.e. $70 \%$, and approximately equally distributed between the eastern and western quadrants, i.e. $47 \%$ versus $53 \%$ (Fig. 1c). Hence, doxycycline is most likely to be more expensive and has an equal probability of being less or more effective. Figure 1d reports the CEAC for the number of exacerbations. It shows that at a willingness-to-pay threshold of $€ 0$ per exacerbation avoided, the probability of doxycycline being cost-effective is $26 \%$, and that this probability increases to $43 \%$ at a willingness-to-pay threshold of $€ 34,000$ per exacerbation avoided.

\subsection{Sensitivity Analysis}

Results of the sensitivity analysis are reported in Table 4 . From the healthcare system perspective, total costs still tended to be higher for the doxycycline group compared to the placebo group, but the difference between arms was smaller (i.e. $€ 328 ; 95 \% \mathrm{CI}-2791$ to 4409). The smaller difference decreased the ICER to $€ 12,358$ per QALY, and increased the number of pairs located in the southern (fewer costs) and eastern (more effective) quadrants of the CE plane to $41 \%$ and $75 \%$, respectively (Fig. 2a). Hence, the probability

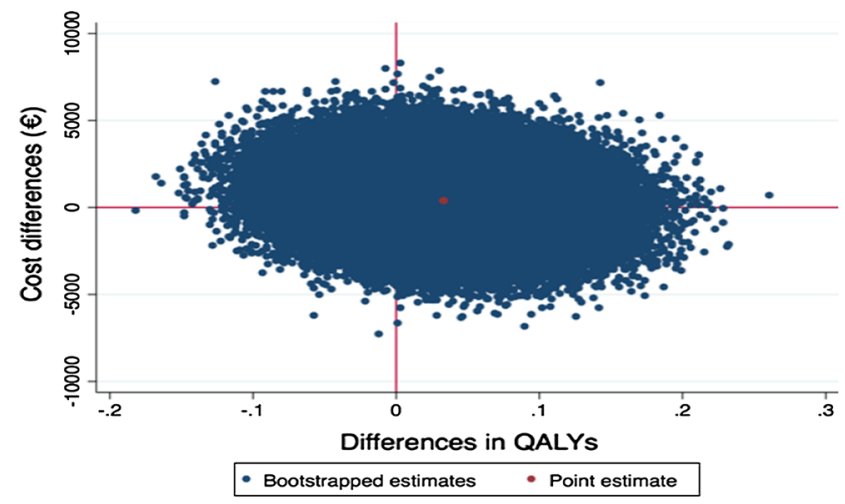

(A) Cost-effectiveness plane for QALYs

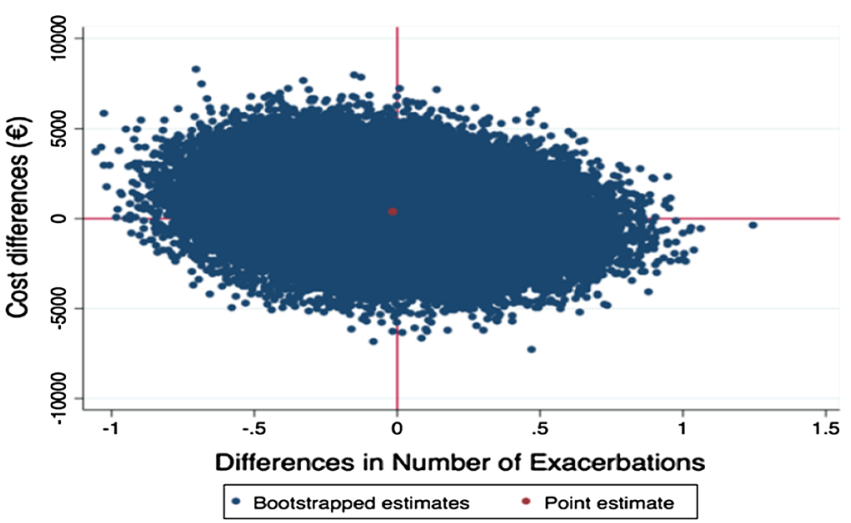

(c) Cost-effectiveness plane for Number of exacerbations of doxycycline being cost-effective increased to $42 \%$ at a willingness-to-pay threshold of $€ 0$ per QALY and $61 \%$ at a willingness-to-pay threshold of $€ 34,000$ per QALY (Fig. 2b).

Also, the ICER for the number of exacerbations avoided was lower from the healthcare system perspective, i.e. - €22,905 per exacerbation avoided, and the percentage of pairs located in the northern (more expensive) quadrants decreased to 58\% (Fig. 2c). Despite this, the probability of doxycycline being cost-effective in comparison with placebo was only $42 \%$ and $43 \%$ at willingness-to-pay ratios of $€ 0$ and $€ 34,000$ per exacerbation avoided, respectively.

\section{Discussion}

This study evaluated the cost-effectiveness of treating COPD exacerbations with doxycycline in addition to prednisolone as compared to prednisolone plus placebo from a societal perspective. Total costs in the doxycycline group were higher than in the placebo group, but the difference was not statistically significant. Differences in QALYs and number of exacerbations between

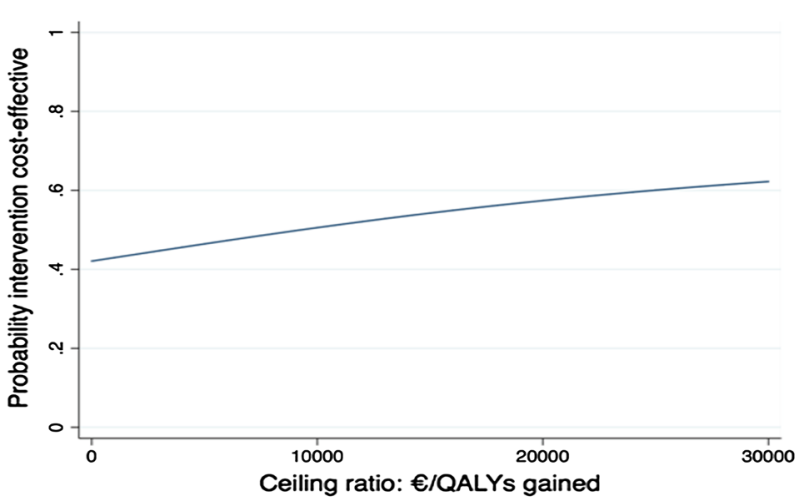

(B) Cost-effectiveness acceptability curve for QALYs

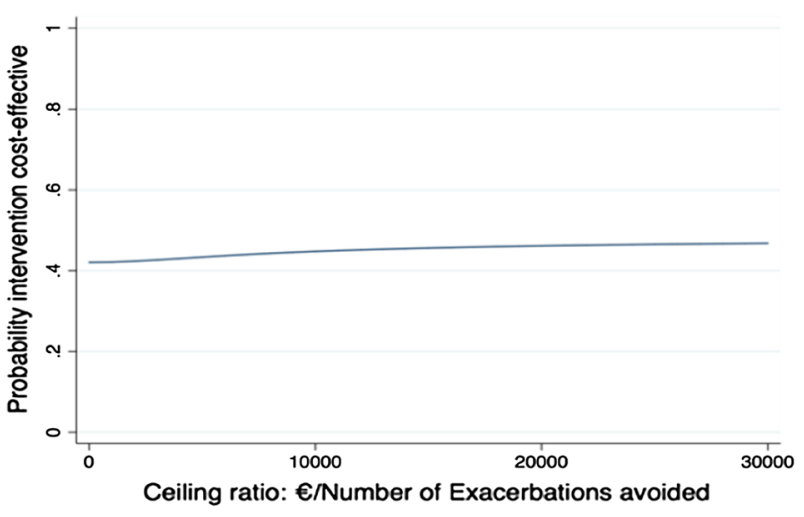

(D) Cost-effectiveness acceptability curve for Number of exacerbations

Fig. 2 Sensitivity analysis cost-effectiveness plane and cost-effectiveness acceptability curve for QALYs and number of exacerbations. QALY quality-adjusted life year 
arms were small and not statistically significant. The ICER was $€ 32,482$ per QALY gained. Although this is potentially within the commonly accepted thresholds of $€ 22,000-34,000$ per QALY, the probability of doxycycline being cost-effective at a willingness-to-pay threshold of $€ 34,000$ was only $61 \%$. For the number of exacerbations avoided, the results showed that doxycycline was less effective and more costly than placebo, and thus, was dominated by placebo. Based on these results, we concluded that using doxycycline in addition to prednisolone is not cost-effective compared to prednisolone plus placebo. To assess the robustness of our findings, we conducted a sensitivity analysis from the healthcare system perspective, confirming that doxycycline was not cost-effective in comparison with prednisolone alone from this perspective.

The rationale for performing this economic evaluation was that in retrospective studies, fewer subsequent exacerbations were observed in patients treated with antibiotics during exacerbations $[12,13]$, and we hypothesised that total costs might be lower in the doxycycline group as compared to the placebo group. In addition, although we found a non-statistically significant difference in short-term treatment failure rates in previous research (odds ratio $0.8 ; 95 \%$ CI $0.41-1.60$ ) [16], we speculated that doxycycline might reduce the number of hospitalisations. As hospitalisations are the key drivers of costs in exacerbations [35], doxycycline would still be cost-effective and therefore justify antibiotic prescription. However, our analysis does not lend strong support for that idea.

The finding that doxycycline is not cost-effective compared to placebo differs from a previous cost-effectiveness analysis on the use of antibiotics versus no antibiotics for the treatment of COPD exacerbations, in which antibiotics were associated with lower costs and better outcomes [15]. There are multiple explanations for this difference, among which are the designs of the studies, i.e. an experimental design versus an observational design, the outcome measures covered, i.e. QALYs versus GP visits, hospital admissions and infections, and the healthcare systems investigated, i.e. The Netherlands versus UK.

This study has a number of important strengths. It represents, to the best of our knowledge, the first cost-effectiveness analysis investigating the long-term effects of doxycycline administered in conjunction with prednisolone versus prednisolone alone for the treatment of COPD acute exacerbations in an outpatient setting. All patients included had COPD confirmed by spirometry. It was conducted alongside a pragmatic randomised controlled trial, which implied prospective collection of cost and effect data and a long-term evaluation of the intervention in a setting generalisable to actual clinical practice. The study employed a societal perspective, meaning that detailed measurements of all costs regardless of the payers were performed, which allows for identifying shifting of costs between different budgets. Finally, the EQ-5D-3L for measuring QALYs was used, which allows cross-programme comparison for health technologies assessment decisions in the Dutch setting, and possibly other settings as well.

Despite these strengths, this study does not come without limitations. First, this study only used Dutch unit costs and the Dutch EQ-5D-3L tariff. As unit costs and tariffs are country specific, this might have limited the generalisability of our findings to different healthcare systems or populations. In addition, differences in costs might also exist, as resource utilisation might differ between countries. Second, only a minority of responders had complete observations for the EQ-5D-3L. This might have affected the quality of our effectiveness estimates. However, baseline differences between complete and non-complete cases were mostly non-significant and the percentage of missing values at each follow-up was generally small. Also, missing data were imputed using multiple imputation by chained equations, which is generally considered the most valid method to account for missing data in economic evaluations $[35,36]$. Third, while the EQ-5D-3L is generally considered valid for use in COPD populations [26], evidence also exist that the measure might miss important generic and specific items of relevance for COPD populations, among which are breathing [38], cough and dyspnoea [39, 40]. Moreover, the EQ-5D-3L was measured at month 1 after randomisation, month 3 and every 3 months thereafter until month 24. Although COPD exacerbations greatly influence quality of life, COPD exacerbations may have occurred at random moments. This might have reduced the ability of this study to detect differences of relevance for the investigated population. Fourth, this study was based on a randomised controlled trial powered to detect differences in time to the next exacerbation and not QALYs. Although this might be one explanation for doxycycline's lack of effectiveness, the consistency between our results and the clinical results reported in van Velzen et al. [16] suggests that this is unlikely.

This study provides evidence for the lack of cost-effectiveness of doxycycline in the treatment of acute COPD exacerbations in an outpatient setting, despite the possibly lower short-term failure rate. As antibiotic resistance is a major concern for public health systems and it is worsened by the inappropriate use of antibiotics, this lack of costeffectiveness discourages their use for COPD exacerbations treated in an outpatient setting.

Author Contributions AF conducted the analyses and wrote the methods, results and discussion sections of the article. PV wrote the introduction section and reviewed the first and second draft of the manuscript. JB provided comments on the first and second draft of the manuscript. GR, PJS and JMP provided comments on the first draft of the introduction and the second draft of the manuscript.

Data Availability Statement The datasets generated during the current study and the software code used to analyse it are not publicly available due to [REASON(S) WHY DATA ARE NOT PUBLIC] but are available from the corresponding author on reasonable request. 


\section{Compliance with Ethical Standards}

Funding This study has been funded by the Netherlands Organization for Health Research and Development, grant number 80-82310-97-10018.

Conflict of Interest Peter J. Sterk and Jan M. Prins were the receivers of the abovementioned grant and declared this as a potential conflict of interest source. Aureliano P. Finch, Patricia van Velzen, Gerben ter Riet and Judith Bosmans declared no conflicts of interest.

Ethical Approval This study was approved by the ethics committee of the Academic Medical Centre and performed in accordance with the ethical standards of the Declaration of Helsinki.
Informed Consent Informed consent was obtained from all individual participants included in the study.

Open Access This article is distributed under the terms of the Creative Commons Attribution-NonCommercial 4.0 International License (http:// creativecommons.org/licenses/by-nc/4.0/), which permits any noncommercial use, distribution, and reproduction in any medium, provided you give appropriate credit to the original author(s) and the source, provide a link to the Creative Commons license, and indicate if changes were made.

\section{Appendix}

See Fig. 3.

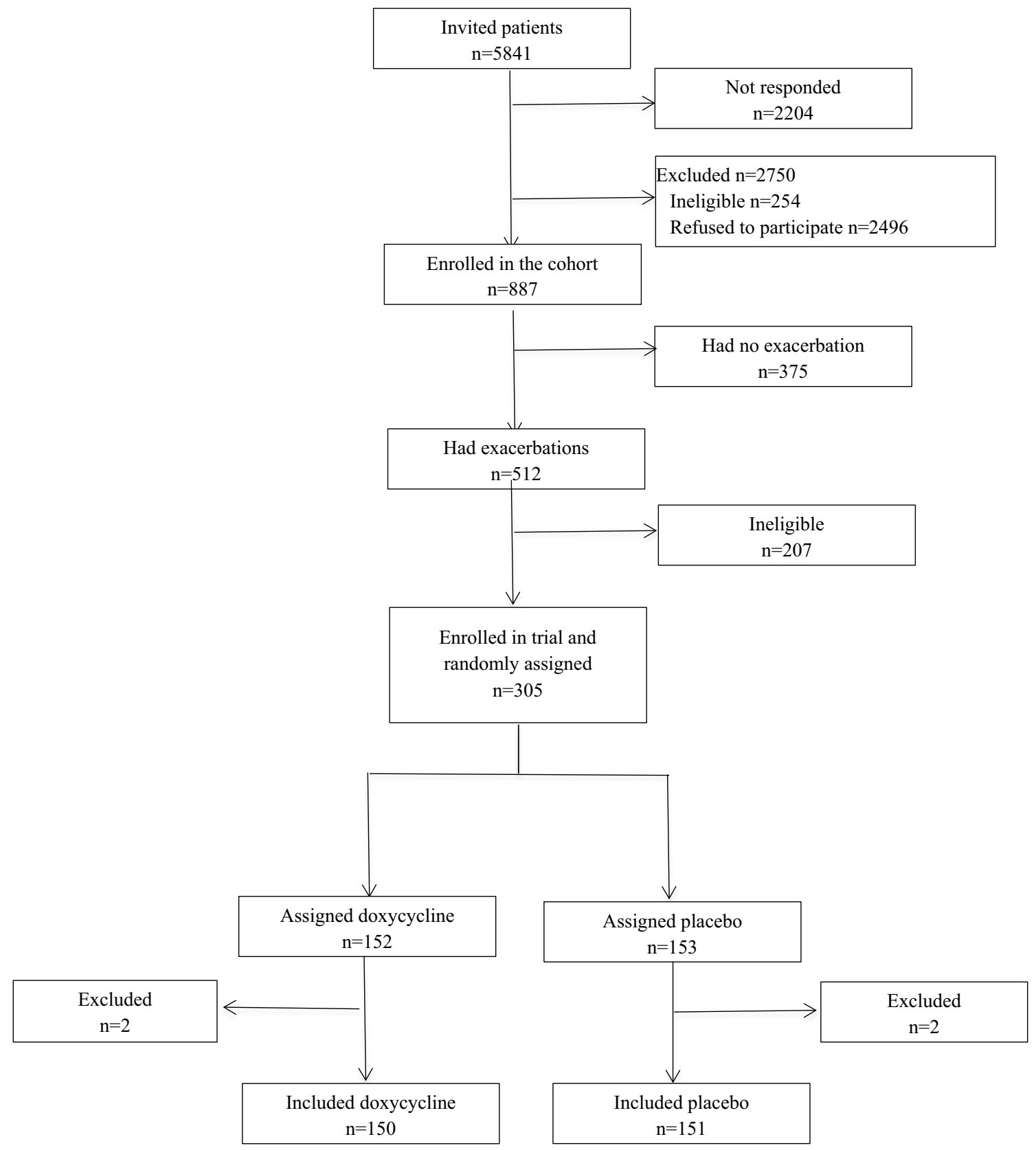

Fig. 3 TEXACOLD trial recruitment flowchart Adapted from Van Velzen et al. [16] 


\section{References}

1. Global Initiative for Chronic Obstructive Lung Disease (GOLD). Global strategy for the diagnosis, management and prevention of COPD (2017 Report). 2017. http://goldcopd.org/ gold-2017-global-strategy-diagnosis-management-prevention -copd/. Accessed 11 June 2018.

2. American Thoracic Society/European Respiratory Society Task Force. Standards for the diagnosis and management of patients with COPD. 2004. http://www.ers-education.org/lrmedia/2004/ pdf/44027.pdf. Accessed 12 June 2018.

3. World Health Organization. Burden of COPD. 2014. http:// www.who.int/respiratory/copd/burden/en/. Accessed 11 June 2018.

4. Wedzicha JA, Miravitlles M, Hurst JR, Calverley PM, Albert RK, Anzueto A, et al. Management of COPD exacerbations: a European Respiratory Society/American Thoracic Society guideline. Eur Respir J. 2017. https://doi.org/10.1183/13993 003.00791-2016.

5. Kessler R, Stahl E, Vogelmeier C, Haughney J, Trudeau E, Lofdahl CG, et al. Patient understanding, detection, and experience of COPD exacerbations: an observational, interview-based study. Chest. 2006;130(1):133-42. https://doi.org/10.1378/chest 130.1.133.

6. Seemungal TA, Donaldson GC, Paul EA, Bestall JC, Jeffries DJ, Wedzicha JA. Effect of exacerbation on quality of life in patients with chronic obstructive pulmonary disease. Am J Respir Crit Care Med. 1998;157(5 Pt 1):1418-22. https://doi.org/10.1164/ ajrccm.157.5.9709032.

7. Donaldson GC, Seemungal TA, Bhowmik A, Wedzicha JA. Relationship between exacerbation frequency and lung function decline in chronic obstructive pulmonary disease. Thorax. 2002;57(10):847-52.

8. Soler-Cataluna JJ, Martinez-Garcia MA, Roman Sanchez P, Salcedo E, Navarro M, Ochando R. Severe acute exacerbations and mortality in patients with chronic obstructive pulmonary disease. Thorax. 2005;60(11):925-31. https://doi.org/10.1136/ thx.2005.040527.

9. Toy EL, Gallagher KF, Stanley EL, Swensen AR, Duh MS. The economic impact of exacerbations of chronic obstructive pulmonary disease and exacerbation definition: a review. COPD. 2010;7(3):214-28. https://doi.org/10.3109/15412 555.2010 .481697

10. Suijkerbuijk AW, de Wit GA, Wijga AH, Heijmans M, Hoogendoorn M, Rutten-van Molken M, et al. Societal costs of asthma, COPD and respiratory allergy. Ned Tijdschr Geneeskd. 2013;157(46):A6562.

11. Vollenweider DJ, Jarrett H, Steurer-Stey CA, Garcia-Aymerich J, Puhan MA. Antibiotics for exacerbations of chronic obstructive pulmonary disease. Cochrane Database Syst Rev. 2012;12:CD010257. https://doi.org/10.1002/14651858.cd010257.

12. Roede BM, Bresser P, Bindels PJ, Kok A, Prins M, ter Riet G, et al. Antibiotic treatment is associated with reduced risk of a subsequent exacerbation in obstructive lung disease: an historical population based cohort study. Thorax. 2008;63(11):968-73. https://doi.org/10.1136/thx.2008.095349.

13. Roede BM, Bresser P, Prins JM, Schellevis F, Verheij TJ, Bindels PJ. Reduced risk of next exacerbation and mortality associated with antibiotic use in COPD. Eur Respir J. 2009;33(2):282-8. https://doi.org/10.1183/09031936.00088108.

14. Llor C, Moragas A, Hernandez S, Bayona C, Miravitlles M. Efficacy of antibiotic therapy for acute exacerbations of mild to moderate chronic obstructive pulmonary disease. Am J Respir Crit Care Med. 2012;186(8):716-23. https://doi.org/10.1164/ rccm.201206-0996OC.
15. Ronaldson SJ, Raghunath A, Torgerson DJ, Van Staa T. Costeffectiveness of antibiotics for COPD management: observational analysis using CPRD data. ERJ Open Res. 2017. https:// doi.org/10.1183/23120541.00085-2016.

16. van Velzen P, Ter Riet G, Bresser P, Baars JJ, van den Berg BTJ, van den Berg JWK, et al. Doxycycline for outpatient-treated acute exacerbations of COPD: a randomised double-blind placebo-controlled trial. Lancet Respir Med. 2017;5(6):492-9. https://doi.org/10.1016/s2213-2600(17)30165-0.

17. Brooks R. EuroQol: the current state of play. Health Policy. 1996;37(1):53-72.

18. van Roijen L, Essink-Bot ML, Koopmanschap MA, Bonsel G, Rutten FFH. Labour and Health status in economic evaluation of health care. Int J Technol Assess Health Care. 1996;12:405-15.

19. Hakkaart-van Roijen L, Van der Linden N, Bouwmans C, Kanters T, Tan SS. Kostenhandleiding. Methodologie van kostenonderzoek en referentieprijzen voor economische evaluaties in de gezondheidszorg. 2015. https://www.zorginstituutnederland.nl/ binaries/zinl/documenten/publicatie/2016/02/29/richtlijn-voorhet-uitvoeren-van-economische-evaluaties-in-de-gezondheid szorg/Richtlijn+voor+het+uitvoeren+van+economische+evalu aties+in+de+gezondheidszorg+\%28verdiepingsmodules\%29.pdf. Accessed June 122018.

20. Z-index. https://www.Z-index.nl/g-standaard. Accessed 12 June 2018.

21. Kanters TA, Bouwmans CAM, van der Linden N, Tan SS, Hakkaart-van Roijen L. Update of the Dutch manual for costing studies in health care. PLoS One. 2017;12(11):e0187477. https://doi. org/10.1371/journal.pone.0187477.

22. Zorginstituut Nederland. Guideline for conducting economic evaluations in healthcare. 2016. https://www.zorginstituutne derland.nl/publicaties/publicatie/2016/02/29/richtlijn-voor-hetuitvoeren-van-economische-evaluaties-in-de-gezondheidszorg. Accessed 11 June 2018.

23. National Institute for Health and Clinical Excellence. Chronic obstructive pulmonary disease in over $16 \mathrm{~s}$ : diagnosis and management. NICE guideline [CG101]. https://www.nice.org.uk/guida nce/CG101/chapter/1-Guidance\#management-of-exacerbationsof-copd. http://www.nice.org.uk/guidance/cg101/chapter/1-recom mendations\#management-of-exacerbations-of-copd. Accessed 3 June 2018.

24. Lamers LM, Stalmeier PF, McDonnell J, Krabbe PF, van Busschbach JJ. Measuring the quality of life in economic evaluations: the Dutch EQ-5D tariff. Ned Tijdschr Geneeskd. 2005;149(28):1574-8.

25. Richardson J, McKie J, Bariola E. Multiattribute utility instruments and their use. Encyclopedia of Health Economics. San Diego: Elsevier Science; 2014.

26. Finch AP, Brazier JE, Mukuria C. What is the evidence for the performance of generic preference-based measures? A systematic overview of reviews. Eur J Health Econ. 2018;19(4):557-70. https ://doi.org/10.1007/s10198-017-0902-x.

27. Seemungal TAR, Donaldson GC, Bhowmik A, Jeffries DJ, Wedzicha JA. Time course and recovery of exacerbations in patients with chronic obstructive pulmonary disease. Am J Respir Crit Care Med. 2000;161(5):1608-13. https://doi.org/10.1164/ajrcc m.161.5.9908022.

28. Faria R, Gomes M, Epstein D, White IR. A guide to handling missing data in cost-effectiveness analysis conducted within randomised controlled trials. Pharmacoeconomics. 2014;32(12):1157-70. https://doi.org/10.1007/s4027 3-014-0193-3.

29. White IR, Royston P, Wood AM. Multiple imputation using chained equations: issues and guidance for practice. Stat Med. 2011;30(4):377-99. https://doi.org/10.1002/sim.4067. 
30. Rubin DB. Multiple imputation for nonresponse in surveys. New York: Wiley; 1987.

31. Willan AR, Briggs AH, Hoch JS. Regression methods for covariate adjustment and subgroup analysis for non-censored costeffectiveness data. Health Econ. 2004;13(5):461-75. https://doi. org/10.1002/hec.843.

32. Efron B. Missing data, imputation, and the bootstrap. J Am Stat Assoc. 1994;89(426):463-75. https://doi.org/10.1080/01621 459.1994.10476768.

33. Black WC. The CE plane: a graphic representation of costeffectiveness. Med Decis Making. 1990;10(3):212-4. https://doi. org/10.1177/0272989x9001000308.

34. Fenwick E, O’Brien BJ, Briggs A. Cost-effectiveness acceptability curves-facts, fallacies and frequently asked questions. Health Econ. 2004;13(5):405-15. https://doi.org/10.1002/hec.903.

35. Andersson F, Borg S, Jansson SA, Jonsson AC, Ericsson A, Prutz $\mathrm{C}$, et al. The costs of exacerbations in chronic obstructive pulmonary disease (COPD). Respir Med. 2002;96(9):700-8.

36. Burton A, Billingham LJ, Bryan S. Cost-effectiveness in clinical trials: using multiple imputation to deal with incomplete cost data. Clin Trials. 2007;4(2):154-61. https://doi.org/10.1177/17407 74507076914.
37. MacNeil Vroomen J, Eekhout I, Dijkgraaf MG, van Hout H, de Rooij SE, Heymans MW, et al. Multiple imputation strategies for zero-inflated cost data in economic evaluations: which method works best? Eur J Health Econ. 2016;17(8):939-50. https://doi. org/10.1007/s10198-015-0734-5.

38. Finch AP, Brazier JE, Mukuria C, Bjorner JB. An exploratory study on using principal-component analysis and confirmatory factor analysis to identify bolt-on dimensions: the EQ-5D case study. Value Health. 2017;20(10):1362-75. https://doi. org/10.1016/j.jval.2017.06.002.

39. Boland MR, van Boven JF, Kocks JW, van der Molen T, Goossens LM, Chavannes NH, et al. Mapping the clinical chronic obstructive pulmonary disease questionnaire onto generic preferencebased EQ-5D values. Value Health. 2015;18(2):299-307. https:// doi.org/10.1016/j.jval.2014.11.006.

40. van der Schans S, Goossens LMA, Boland MRS, Kocks JWH, Postma MJ, van Boven JFM, et al. Systematic review and quality appraisal of cost-effectiveness analyses of pharmacologic maintenance treatment for chronic obstructive pulmonary disease: methodological considerations and recommendations. Pharmacoeconomics. 2017;35(1):43-63. https://doi.org/10.1007/s4027 3-016-0448-2. 